\title{
Short-chain grafting of tetrahydrofuran and 1,4-dioxane cycles on vinylchloride-maleic anhydride copolymer
}

\author{
A. G. Filimoshkin ${ }^{*}$, A. S. Kuchevskaya1, E. M. Berezina1 ${ }^{1}$, V. D. Ogorodnikov² \\ ${ }^{1}$ Tomsk State University, Tomsk, 634050, Russia \\ ${ }^{2}$ Institute of Petroleum Chemistry SB RAS, Tomsk, 634021, Russia
}

Received 27 October 2008; accepted in revised form 24 November 2008

\begin{abstract}
Mass increase of vinylchloride-maleic anhydride (VC-MA) copolymer samples aged in tetrahydrofuran (THF) or in 1,4-dioxane results from chemical interaction of VC-MA macromolecules with 1,4-dioxane or THF. Microstructure of the products of such modification was proved by infrared spectroscopy (IR-) and nuclear magnetic resonance spectroscopy $\left({ }^{13} \mathrm{C}\right.$ NMR and ${ }^{1} \mathrm{H}$ NMR). Mechanism of modification has been proposed. The results of microstructure research of VC-MA samples aged in THF and in 1,4-dioxane coincide with already known data on the reactions of opening of these and other oxygen-containing cycles under mild conditions.
\end{abstract}

Keywords: polymer synthesis, molecular engineering, graft copolymers, vinyl chloride-maleic anhydride copolymers, tetrahydrofuran, 1,4-dioxane

\section{Introduction}

Alternating, statistical and graft copolymers of maleic anhydride (MA) exhibit quite a number of valuable properties. Thus MA and vinyl chloride (VC) copolymers easily enter into various reactions and are considered as convenient initial products for polymer synthesis of new substances utilized as biologically active materials and enzyme carriers, ionites, photographic, pharmaceutical, pore-forming, antifriction materials etc [1]. Copolymers of vinyl monomers with MA are applied in automotive industry [2] and they are also used as the initial reagents to produce novel composite materials. Sodium salts of succinic anhydride derivatives are widely used as dispersants, flocculants and soil modifiers [3]. Biomedical application of the MA copolymers as medicines and their carriers is also of interest.

The VC-MA copolymer easily reacts with water and alcohols [4, 5], sodium azide [6], carbonyl-con- taining solvents and dimethyl sulfoxide [7]. In deuterated acetone medium deuteroexchange was detected in the enol fragments of the macromolecules [8]. The reactions of the VC-MA copolymers with dimethyl formamide molecules proceed as regiospecific to form long-living solvate structures [9].

The present work is aimed at studying chemical modification of the VC-MA copolymer with such cyclic ethers as THF and 1,4-dioxane as a mode of molecular engineering.

\section{Experimental}

The samples of VC-MA copolymer were obtained by radical copolymerization of $\mathrm{MA}$ and $\mathrm{VC}$ at $80^{\circ} \mathrm{C}$ for $24 \mathrm{~h}$ in sealed tubes in 1,2-dichlorethane with benzoyl peroxide (1 mass\%) and with a comonomer ratio of 1:1 [10]. The initial reagents and solvents were thoroughly refined [11]. The IR 
spectra were recorded on a FTIR-Spectrometer Nicolet 5700 (Thermo Electron, USA) in tablets with $\mathrm{KBr}(2 \mathrm{mg} / 300 \mathrm{mg} \mathrm{KBr}) ;{ }^{1} \mathrm{H}$ and ${ }^{13} \mathrm{C}$ NMR spectra - on a Bruker Avance AV 300 NMR Spectrometer (Bruker, Germany) with operating frequency 300 and $75 \mathrm{MHz}$ accordingly at $25^{\circ} \mathrm{C}$ in $\mathrm{d}_{6}$-acetone (10 mass\% solutions), where acetone was used as an internal standard. All experiments were carried out under conditions excluding any contact with atmospheric moisture to prevent hydrolysis of the succinic anhydride rings.

The process of grafting of THF and 1,4-dioxane was carried out in tightly closed flasks $(0.5 \mathrm{~g}$ of VC-MA and $4 \mathrm{ml}$ of the solvent). In a day homogeneous viscous solutions were carefully carried into the preliminary weighted Petri dishes and left for a week to remove the solvents. The formed films were dried in vacuo to constant mass. The mass of the aged samples increased by $8-10$ mass $\%$ as compared to the mass of the initial VC-MA copolymer. Calculation of grafting efficiency: degree of polymerization is $c a 600 ; 30 \mathrm{~mol} \%$ (initial) of repeated units are tautomerized in the enol forms (see below) [12, 13]. If all enol forms had been involved in grafting the mass increase of the sample treated by THF would have been 12 mass $\%$. The $8-10$ mass $\%$ increase indicates that $60 \mathrm{~mol} \%$ of the initial enol forms participate in grafting.

\section{Results and discussion}

Due to the action of different catalysts $(\mathrm{HCl}$, $\left(\mathrm{CH}_{3} \mathrm{CO}\right)_{2} \mathrm{O},\left(\mathrm{POCl}_{3}+\mathrm{H}_{2} \mathrm{SO}_{4}\right)$ and $\left.\mathrm{H}_{3} \mathrm{PO}_{4}\right)$ THF
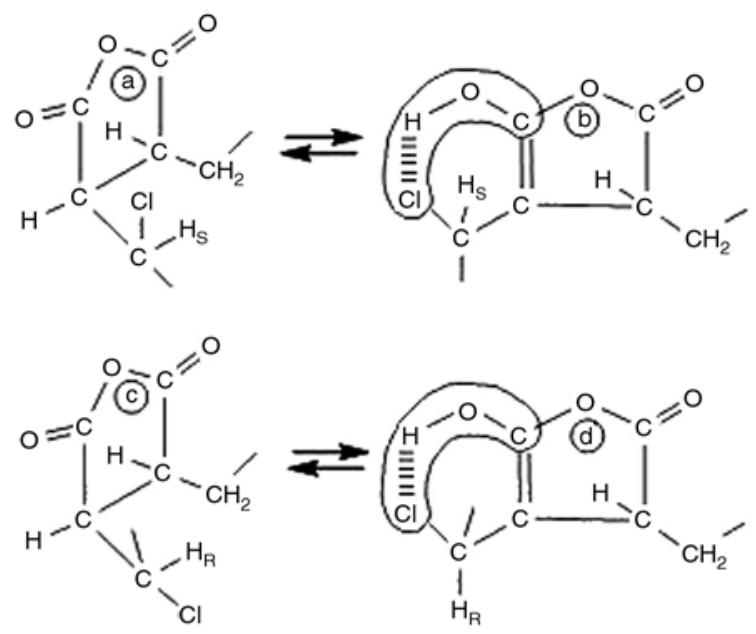
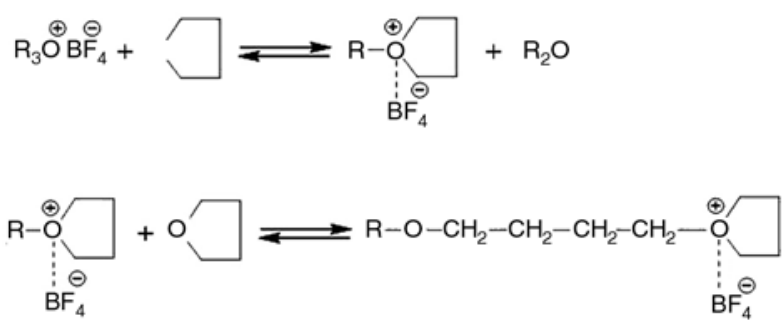

Figure 1. Mechanism of THF cycles breakage followed by polymerization

cycles open under mild conditions [14, 15]. As an example THF cycle opening in the presence of $\mathrm{R}_{3} \mathrm{O} \cdot \mathrm{BF}_{4}$ is accompanied by polymerization (Figure 1). The other reactions of oxygen-containing cycle polymerization are also known [16].

Marked increase in the VC-MA copolymer mass after its aging in THF and in 1,4-dioxane media was unexpected. To explain this fact we supposed that certain tautomeric forms of the repeated units of VC-MA copolymer [10] interact with solvent molecules, which open with simultaneous grafting on them.

In the solvents of various nature VC-MA copolymer undergoes cycloanhydride-enol tautomerism resulting in dynamic micro structural heterogeneity in the form of enol $\Delta^{6} e n$ (see $b, d, f$ and $h$ in Figure 2) and dienol derivatives of furan being tautomers of jointly VC and MA comonomer units, which afterwards appear in the macromolecular chains as succinic anhydride derivatives [10, 17] Formation of $\Delta^{6}$ en tautomeric forms is accompanied by appearance of aromatic carbon atom signals in the ${ }^{13} \mathrm{C}$ NMR spectrum of the VC-MA
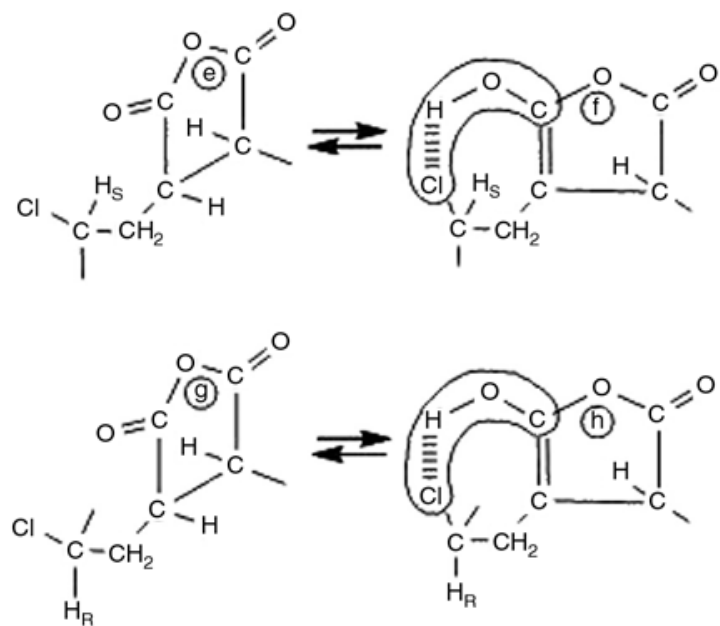

Figure 2. Dynamic microstructure of the VC-MA macromolecules (a, c, e and g - comonomeric units of VC and MA; b, $\mathrm{d}, \mathrm{f}$ and $\mathrm{h}-\Delta^{6}$ en tautomeric forms of the a, c, e and $\mathrm{g}$ units. $\mathrm{H}_{\mathrm{S}}$ and $\mathrm{H}_{\mathrm{R}}-$ hydrogen atoms attached to the $\mathrm{S}-$ or R-chiral carbon atoms). 

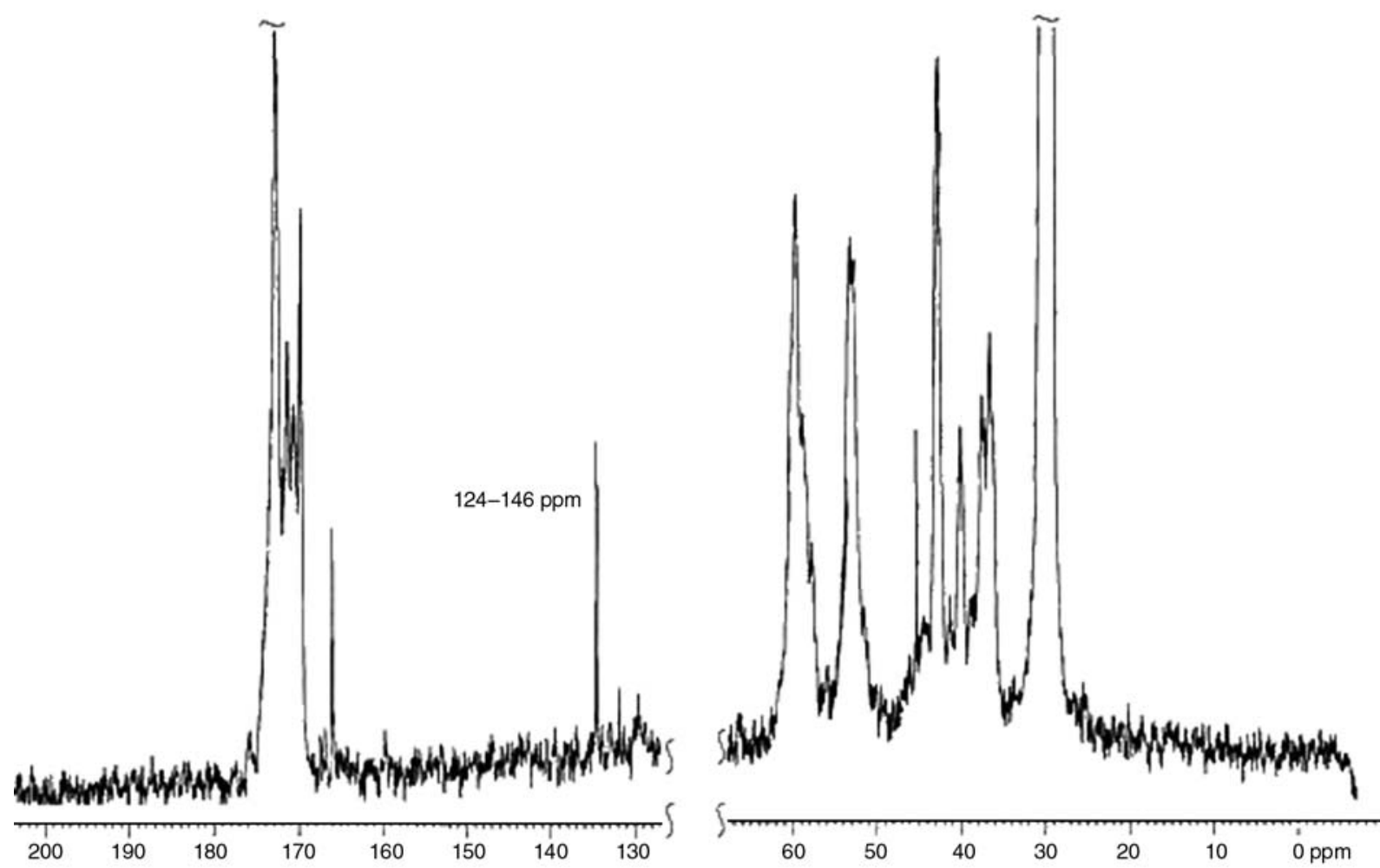

Figure 3. The ${ }^{13} \mathrm{C}$ NMR spectrum of the original VC-MA sample

sample in the region of 124-146 ppm (Figure 3) [18]. Under the selected synthesis conditions macromolecules of equimolar VC-MA copolymer were earlier found [12] to consist of the statistical sequence of the VC-MA repeat units $(\sim 67 \mathrm{~mol} \%)$ and their $\Delta^{6} e n$ tautomers ( $\sim 33 \mathrm{~mol} \%$ ) (Figure 2) which was proved by mathematical modeling of the microstructure of the macromolecules in view [13]. It was suggested just the $\left[\mathrm{Cl} \ldots \mathrm{H}-\mathrm{O}-\mathrm{C}^{\delta+}\right]^{\#}$ ensembles (Figure 2) that are the reaction centers causing cycle opening. Their high-energy transition state promotes formation of oxonium ions causing breakage of THF and 1,4-dioxane cycles: Figure 4 presents a mechanism of THF cycles grafting on the macromolecules of the VC-MA copolymer. As a result of nucleophilic attack at the $\mathrm{C}-\mathrm{Cl}$ carbon atom (a) an oxonium compound is being formed (b) with simultaneous bonding breakage of the intramolecular hydrogen bond and hydrogen migration to its original position (c), THF cycle being opened at the same time $(d)$.

To determine microstructure of VC-MA macromolecules modified with THF we used IR-, ${ }^{13} \mathrm{C}$ and ${ }^{1} \mathrm{H}$ NMR-spectroscopy. The IR spectrum of VCMA aged in THF exhibits new bands: $V_{-}{ }_{-}-O_{-}-$ $\left(1174 \mathrm{~cm}^{-1}\right), v_{\mathrm{CH}_{2}}\left(2588\right.$ and $\left.2893 \mathrm{~cm}^{-1}\right), \delta_{\mathrm{CH}_{2}}$ $\left(1368 \mathrm{~cm}^{-1}\right)$ and $\delta_{\mathrm{CH}}\left(876\right.$ and $\left.835 \mathrm{~cm}^{-1}\right)$, and the band intensity of $\delta_{\mathrm{CH}_{2}}\left(1440 \mathrm{~cm}^{-1}\right)$ highly increases (see 1, 2 in Figure 5). The substantial change in the $\mathrm{C}-\mathrm{Cl}$ carbon environment (Figures $4 \mathrm{a}$ and $4 \mathrm{~d}$ ) leads to the increased intensity of the $v_{\mathrm{CCl}}$ absorption band $\left(619 \mathrm{~cm}^{-1}\right)$. Besides one observes redistribu-

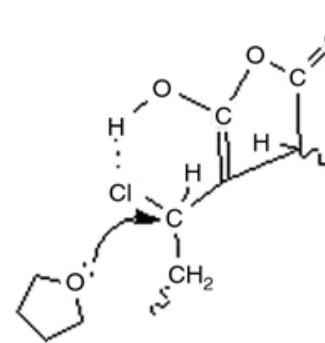

a)

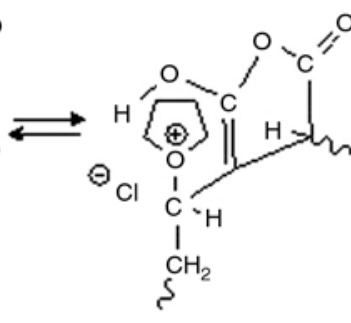

b)<smiles>COC1CCCO1</smiles>

c)<smiles>CCC(OCCCl)C1C(=O)OC(=O)C1C</smiles>

d)

Figure 4. Mechanism of THF cycles grafting on the VC-MA macromolecules 


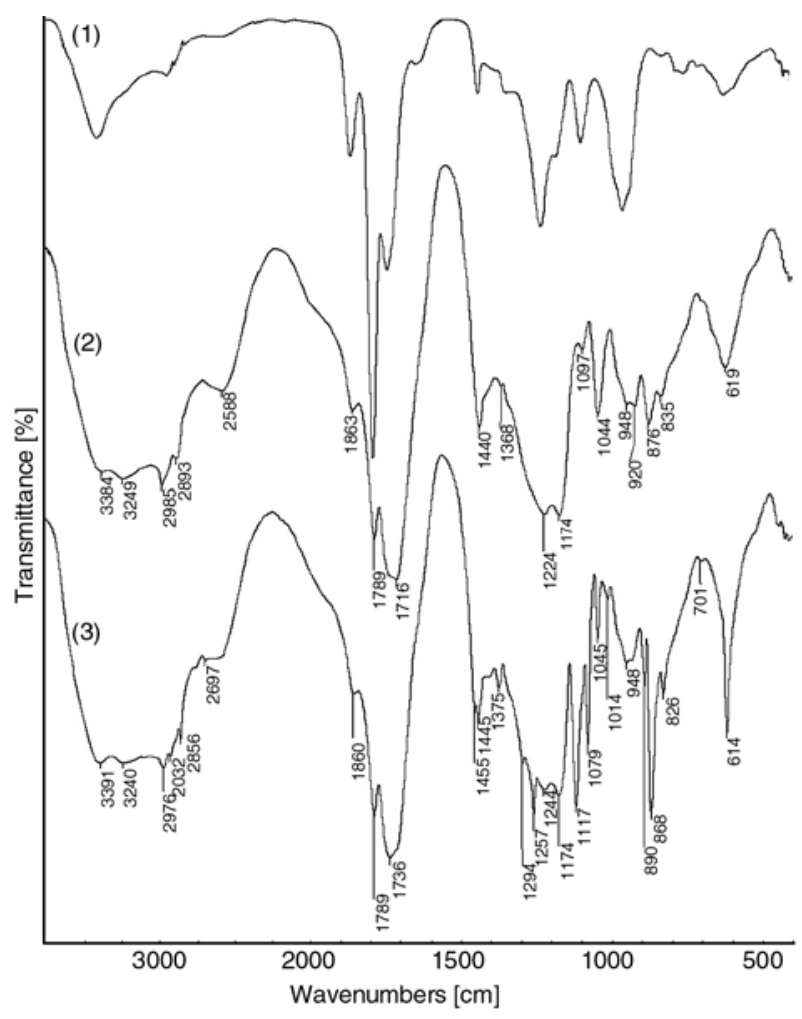

Figure 5. The IR spectra of the original VC-MA sample (1), of the VC-MA sample aged in THF (2) and of the VC-MA sample aged in 1,4-dioxane (3)

tion of band intensities at 1863, 1789 and $1716 \mathrm{~cm}^{-1}$ caused by $v_{\mathrm{C}=\mathrm{O}}$ of the succinic anhydride ring.

The ${ }^{1} \mathrm{H}$ NMR spectrum of the same VC-MA sample exhibits multiplets at 3.6-3.7 and 1.7-1.8 ppm (Figure 6b; unequivalent methylene groups of the attached THF molecules $\mathrm{Cl}-\mathbf{C H}_{2}-\mathrm{CH}_{2}-\mathrm{CH}_{2}-$ $\mathbf{C H}_{2}-\mathrm{O}_{-}$) absent in the spectrum of the initial VCMA sample (Figure 6a). In the ${ }^{13} \mathrm{C}$ NMR spectrum two additional signals at 26 and $68 \mathrm{ppm}$ of unequivalent $\mathrm{CH}_{2}$ carbons are registered (Figure 7a).

If polymerization which is accompanied by THF cycles opening is well investigated, the six-member cycles of 1,4-dioxane are known to form peroxides rather easily [19], but they do not undergo polymerization [15]. After aging of the VC-MA samples in the freshly refined 1,4-dioxane its mass substantially increases. A probable mechanism of 1,4dioxane interaction with $\Delta^{6} e n$ reaction centers is presented in Figure 8.

The changes in the region of $4000-1500 \mathrm{~cm}^{-1}$ in the IR spectrum of VC-MA aged in 1,4-dioxane (see 3 in Figure 5) are identical to the above described changes observed in the IR spectrum of the VC-MA aged in THF. Besides new absorption

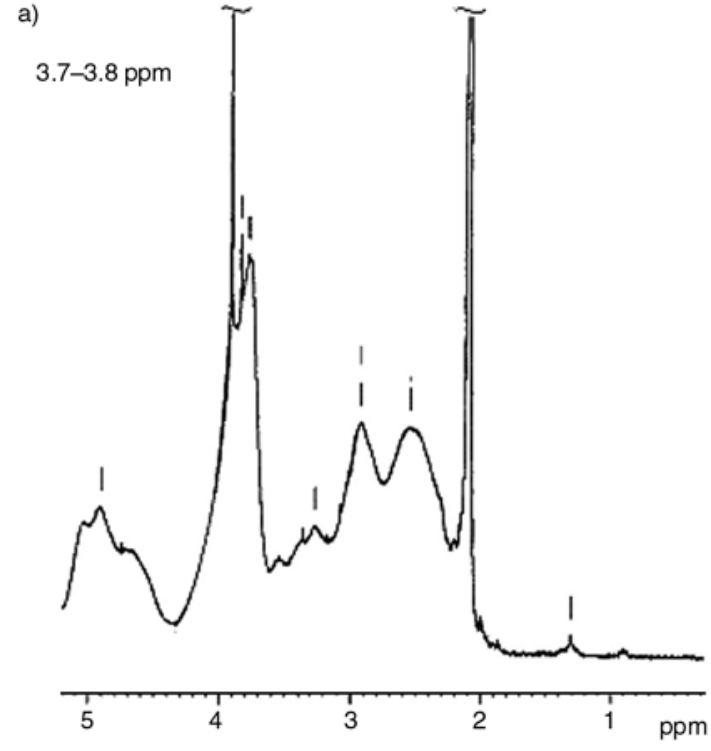

b)

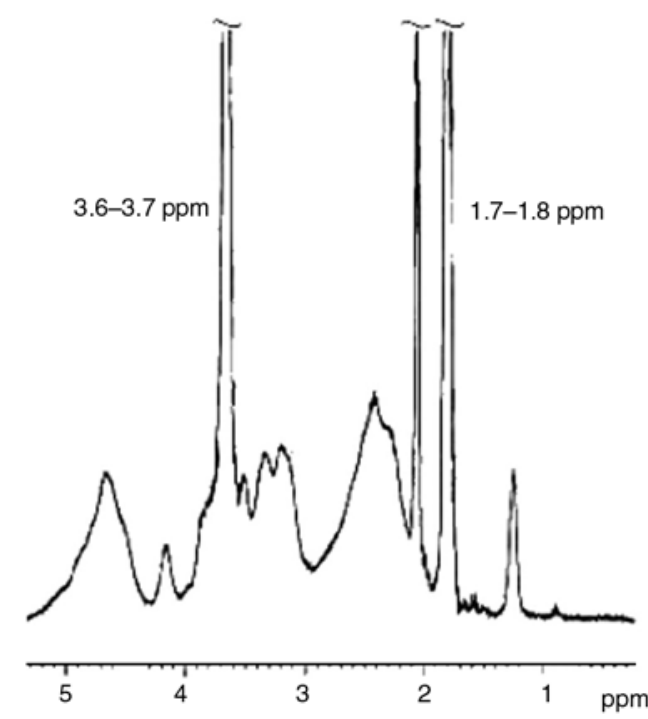

c)

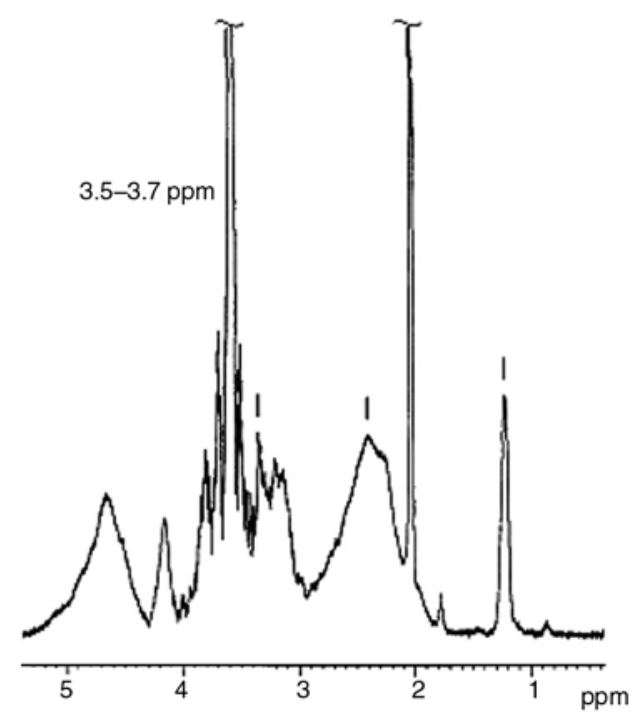

Figure 6. The ${ }^{1} \mathrm{H}$ NMR spectra the original VC-MA sample (a), of the VC-MA sample aged in THF (b) and of the VC-MA sample aged in 1,4-dioxane (c) 

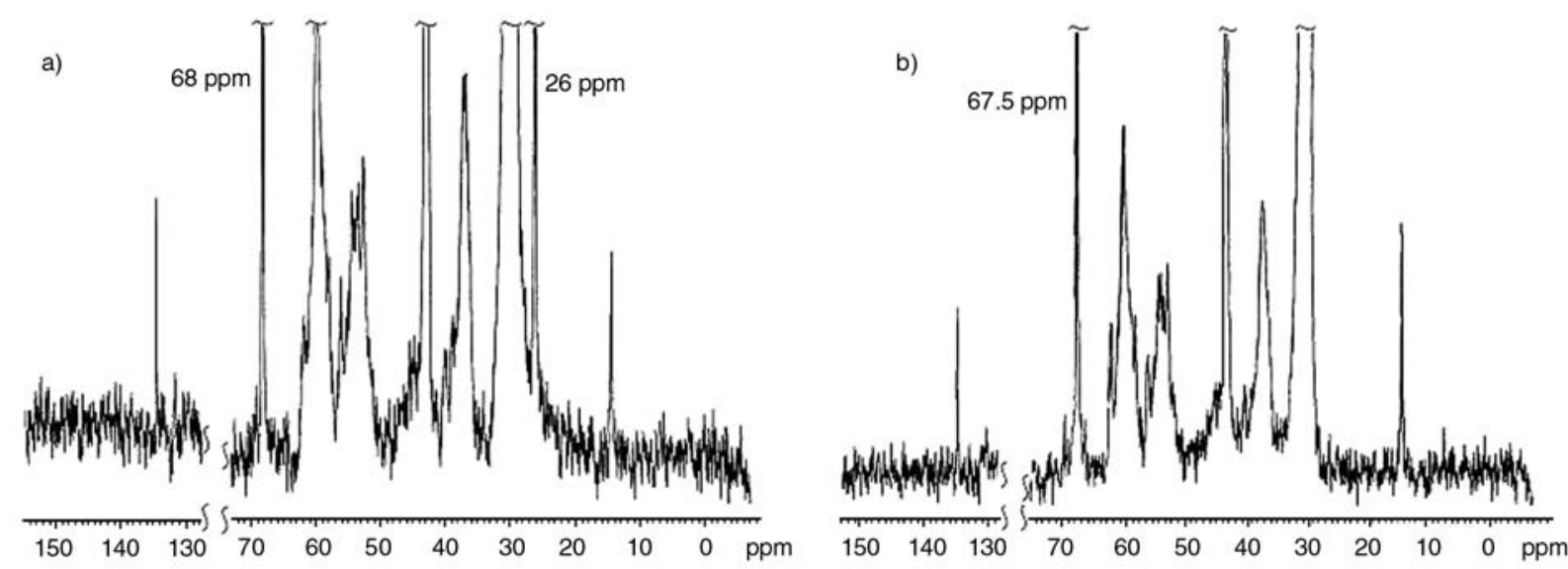

Figure 7. The ${ }^{13} \mathrm{C}$ NMR spectra of the VC-MA sample aged in THF (a) and of the VC-MA sample aged in 1,4-dioxane (b)

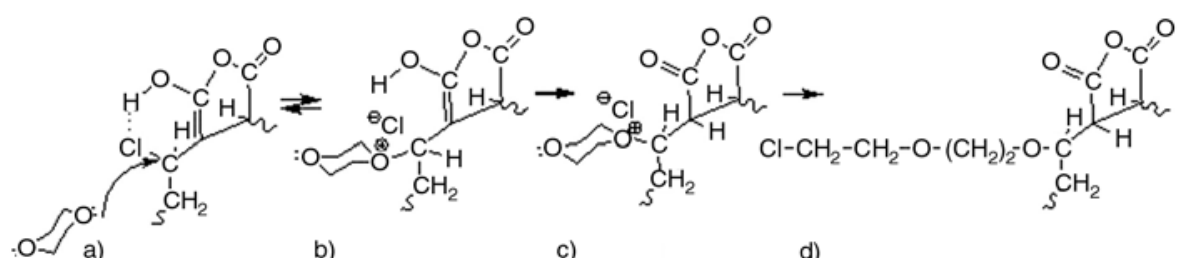

b)

c)

d)

Figure 8. Mechanism of 1,4-dioxane grafting on the VC-MA macromolecules

bands $v_{-C-O-C-}\left(1117 \mathrm{~cm}^{-1}\right)$ and $\delta_{\mathrm{CH}}(868$ and $826 \mathrm{~cm}^{-1}$ ) appear. Absorption bands of $\delta_{\mathrm{CH}_{2}}$ $\left(1375 \mathrm{~cm}^{-1}\right)$ and $\mathrm{v}_{\mathrm{CCl}}\left(614 \mathrm{~cm}^{-1}\right)$ become more pronounced. The intensity of the $\delta_{\mathrm{CH}_{2}}$ absorption band $\left(1445 \mathrm{~cm}^{-1}\right)$ increases.

The ${ }^{1} \mathrm{H}$ NMR spectrum of the VC-MA sample aged in 1,4-dioxane has an intensive multiplet at 3.5$3.7 \mathrm{ppm}$ referred to the equivalent $\mathrm{CH}_{2}$ protons of the dioxane fragments attached (Figure 6c). A new signal at $67.5 \mathrm{ppm}$ of $\mathrm{CH}_{2}$ carbon of the same fragments was registered in the ${ }^{13} \mathrm{C}$ NMR spectrum of the same sample (Figure 7b).

\section{Conclusions}

Thus reactive $\Delta^{6}$ en tautomeric forms of the repeat units of the VC-MA copolymer react with THF and 1,4-dioxane molecules to form short chain graft copolymers. In other words, the high energy transition state of the ensembles $\left[\mathrm{Cl} \ldots \mathrm{H}-\mathrm{O}-\mathrm{C}^{\delta+}\right]^{\#}$ appear to play the role of catalytic sites in situ. On an average $\mathrm{ca} 60 \mathrm{~mol} \%$ of the $\Delta^{6}$ en tautomeric forms of macromolecules is involved in grafting.

\section{References}

[1] Trivedi B. C., Culbertson B. M.: Maleic anhydride. Plenum Press, New York (1982).
[2] Kaczmarek H., Felczak A., Szalla A.: Studies of photochemical transformations in polystyrene and styrene-maleic anhydride copolymer. Polymer Degradation and Stability, 93, 1259-1266 (2008). DOI: $10.1016 /$ j.polymdegradstab.2008.04.011

[3] Carja G., Chitanu G. C., Kameshima Y., Chiriac H., Okada K.: LDH-maleic anhydride copolymers as new hybrid materials and their textural organisation. Applied Clay Science, 41, 107-112 (2008). DOI: $10.1016 /$ j.clay.2007.10.002

[4] Bulantseva V. N., Berezina E. M., Chernov E. B., Filimoshkin A. G.: Characteristics of vinyl chloridemaleic anhydride copolymer hydrolysis. Vysokomolekulyarnye Soedinenya, Series B, 33, 54-60 (1992).

[5] Pribytkov E. G., Eremina N. S., Terent'eva G. A., Chernov E. B., Filimoshkin A. G.: Esterification of vinyl chloride-maleic anhydride copolymer by alcohols. Russian Journal of Applied Chemistry, 71, 313317 (1998).

[6] Pavlova T. V., Terent'eva G. A., Chernov E. B., Filimoshkin A. G.: Interaction of vinyl chloride-maleic anhydride copolymer with sodium azide in dimethylformamide. Polymer Science, Series A, 36, 631-636 (1994).

[7] Filimoshkin A. G., Chernov E. B., Terent'eva G. A., Berezina E. M., Telegin A. G.: Intermolecular interactions between vinyl chloride-maleic anhydride copolymer and carbonyl-containing solvents and dimethyl sulfoxide. Polymer Science, Series A, 39, 1312-1316 (1997). 
[8] Berezina E. M., Pavlova T. V., Terent'eva G. A., Chernov E. B., Filimoshkin A. G.: Effect of solvent on the structure of the solutions of poly(vinyl chlorideco-maleic anhydride). Polymer Science, Series A, 37, 1254-1259 (1995).

[9] Safronova M. S, Berezina E. M., Terent'eva G. A., Chernov, E. B., Filimoshkin A. G.: Regiospecifity of reactions of vinyl chloride-maleic anhydride copolymer with dimethylformamide. Russian Journal of Applied Chemistry, 74, 1554-1558 (2001). DOI: 10.1023/A:1013725706655

[10] Filimoshkin A. G., Terent'eva G. A., Berezina E. M., Pavlova T. V.: A novel behavior of copoly (vinylchloride-maleic anhydride). Journal of Polymer Science, Part A: Polymer Chemistry, 31, 1911-1914 (1993).

[11] Gordon A. J., Ford R. A.: The chemist's companion. Wiley, New York (1972).

[12] Filimoshkin A. G., Chernov E. B., Terent'eva G. A., Berezina E. M., Safronova M. S.: Microstructure of vinyl chloride-maleic anhydride copolymer in condensed state. Russian Journal of Applied Chemistry, 74, 298-304 (2001).

[13] Pribytkov E. G., Berezina E. M., Eremina N. S., Terent'eva G. A., Chernov E. B., Filimoshkin A. G.: Mathematical modeling of the microstructure of a vinyl chloride-maleic anhydride copolymer in solution. Polymer Science, Series A, 39, 932-937 (1997).
[14] Khimicheskaya entsiklopediya (Chemical encyclopedia). Edited by Zefirov N. S. Bol'shaya Rosiyskaya Entsiklopediya, Moscow, Vol 4 (1995).

[15] Odian G.: Principles of polymerization. Wiley, New York (2004).

[16] Ravve A.: Principles of polymer chemistry. Plenum Press, New York, London (1995).

[17] Filimoshkin A. G., Kosolapova V. F., Petrenko T. V., Aksenov V. S., Poleshchuk O. Kh.: New type of prototropic tautomerism involving carbon, hydrogen and oxygen atoms. Russian Journal of Organic Chemistry, 40, 462-466 (2004). DOI: 10.1023/B:RUJO.0000036062.82821.ab

[18] Pavlova T. V., Terent'eva G. A., Filimonov V. D., Chernov E. B., Filimoshkin A. G.: New views on the microstructure of vinyl chloride-maleic anhydride copolymer in solution. Russian Journal of Applied Chemistry, 72, 1600-1603 (1999).

19] Khimicheskaya entsiklopediya (Chemical encyclopedia). Edited by Knunyants I. L. Sovetskaya Entsiklopediya, Moscow, Vol 2 (1990). 